\title{
The Documentation and Characteristics of Hospitalized IPV Patients Using Electronic Medical Records Data: a Follow-Up Descriptive Study
}

\author{
Salla Kivelä ${ }^{1}$ (D) Tuija Leppäkoski $^{1,2} \cdot$ Janne Ruohoniemi ${ }^{2} \cdot$ Hannu Puolijoki $^{2} \cdot$ Eija Paavilainen $^{1,2}$
}

Published online: 28 June 2019

(C) The Author(s) 2019

\begin{abstract}
Intimate partner violence (IPV) is a serious health problem worldwide but is often not identified by health services. The aim of this study was to describe the characteristics of healthcare patients and documentation compared to the baseline study (20082012). The sample $(N=798)$ consisted of visits to a central hospital in Finland that had been marked with the ICD-10 codes for assault (X85-Y09) and physical abuse (T74.1) during the years 2013-2017. The data was analyzed with content analysis. Among the IPV visits $(n=110)$, partner- or spouse-related perpetrator coding was poor $(11 \%)$. Victims experienced multiple injuries, and the violence increased with female gender, alcohol, and nighttime. The insufficient use of perpetrator codes underestimates the incidence of IPV and minimizes their usefulness for surveillance.
\end{abstract}

Keywords Family violence $\cdot$ Intimate partner violence $\cdot$ Documentation $\cdot$ ICD-10

Intimate partner violence (IPV) is a serious health problem that imposes a major burden on public health and well-being. IPV occurs in all countries and settings and in all socioeconomic, religious, and cultural groups. Every year, violence causes healthcare costs and legal costs, absenteeism from work, and loss of productivity (Krug et al. 2002; World Health Organization [WHO] 2010). IPV includes physical violence, sexual violence, emotional abuse, and controlling behaviors by a partner. A partner is a current or former spouse (married spouse, common-law spouse, civil union spouse, domestic partner), boyfriend or girlfriend, dating partner, or sexual partner (Breiding et al. 2015). Almost one-third of women $(30 \%)$ and men $(29 \%)$ have experienced violence in a relationship (Reid et al. 2008; WHO 2013).

IPV leads to various psychological and physical consequences, including death. Women assaulted by an intimate partner are at a greater risk of injury than other women and have more frequent moderate-to-severe injuries (Zilkens et al. 2017). Violence affects the whole family, and the role of the family is central to the health and well-

Salla Kivelä

Kivela.Salla.E@student.uta.fi

1 Faculty of Social Sciences (Nursing Science), Tampere University, Tampere, Finland

2 The Hospital District of South Ostrobothnia, Seinäjoki, Finland being of individuals (Blinded et al., 2017). Early childhood and adolescent abuse are predictors in the development of IPV perpetration and victimization in adulthood (Costa et al. 2015; Ellonen et al. 2013; Ruddle et al. 2017). According to Widom et al. (2014), child maltreatment increases the risk for the most serious form of IPV involving physical injury. Adults with documented histories of child maltreatment are at an increased risk for a greater number and variety of acts of physical and psychological violence from an intimate partner.

IPV is a significant problem not often identified by health services. Both men and women experience violence, but few seek help from healthcare professionals (Kivelä et al. 2018). Previous studies have shown that victims and perpetrators with violent experiences have more hospital visits, several diagnoses, mismatches between reports, and a higher rate of readmission than patients who have not experienced violence (Chan et al. 2013; Matteoli et al. 2016). IPV victims are most often hit in the head, face, and neck (HFN) areas. Hence, the most common IPV-related injuries localize in the HFN area (Curca et al. 2012; Matteoli et al. 2016; Trojan and Krull 2012). Oral and maxillofacial traumas are very common among women victims, generating high social and economic costs (de Macedo Bernardino et al. 2018). Moreover, most victims present defense injuries on the upper limbs and/or fall-related injuries on the prominent parts of the body. Ideally, the victim should seek healthcare as soon as possible after violence to maximize injury identification. Some lesions 
fade or disappear after only a few days, decreasing characterization and dating accuracy (Curca et al. 2012).

Healthcare professionals have a vital role in both identifying and providing IPV victims with the necessary treatment, support, and care. Health services must be places where patients feel safe and are treated with respect and without stigmatization (McCauley et al. 2017.) According to Leppäkoski et al. (2014), approximately one-third of healthcare professionals had met or treated a patient who had experienced violence on at least one occasion. However, screenings for IPV vary, and very few emergency departments have procedures to identify victims. A lack of general preparedness, can lead to many patients not receiving appropriate care or treatment. The needed preparedness includes regulatory documents, written routines, organized education for personnel, delegation of specific responsibilities to staff, and information about continued support and care (Linnarsson et al. 2013).

\section{ICD-10 Coding in Healthcare}

The International classification of diseases (ICD) is one of the oldest and most important classifications in healthcare. It is used as a coding system in medical databases for any injury or disease. ICD-10 codes are used for statistical purposes, and they can have enormous financial importance because they are used to determine how to allocate resources (WHO 2018). Intentional injuries require codes for both the essential and the external cause of injury. Most often, the essential codes are from "Chapter XIX: Injury, poisoning and certain other consequences of external causes" (S00-T98). This chapter uses the "S" section to code different types of injuries related to single body regions and the "T" section to cover injuries to multiple or unspecified body regions (WHO 2016).

The codes for external cause of injury are from "Chapter XX: External causes of morbidity and mortality" (V01-Y98). These codes are secondary codes used to provide additional information about the cause of an injury. The codes for external cause of injury include the injury mechanism and the identification of the perpetrator's relationship to the assault victim. Perpetrator codes can be added when the code for the first external cause is from the range of interpersonal violence (assault) codes X85-Y09 (WHO 2016).

Unfortunately, the identification and documentation of IPV is still difficult and variable in healthcare. The documentation of injuries, evidence collection, and reports are not always consistently high quality. Assessment by healthcare professionals in forensic documentation and interpretation of injuries can result in a number of benefits for victims, including an increase in positive court outcomes, such as successful prosecution. (Nittis et al. 2013.) According to previous studies, patients' denial of violence, the inconsistency between patients' stories and their physical examinations, and lack of time and resources are the main barriers in identifying violence (Bradbury-Jones et al. 2014; Leppäkoski et al. 2014; McCauley et al. 2017). Professionals need the knowledge and skills for identifying and responding appropriately to disclosures of IPV, which requires a commitment and multidisciplinary collaboration (Leppäkoski et al. 2015).

Research evidence exists regarding the outcomes of IPV, as well as healthcare workers' important position in helping victims or perpetrators (García-Moreno et al. 2005). However, healthcare workers often have stereotypical beliefs about patients who experience IPV. Further training is needed to identify violence and gain knowledge about the dynamics of IPV (Ben Natan et al. 2012; Koistinen and Holma 2015; Leppäkoski et al. 2010). Overall, there is a great need to identify victims of violence and document the care provided in IPV cases. The ICD-10 coding can help victims, healthcare professionals, and researchers in the detection, treatment, and prevention of IPV (Kivelä et al. 2016). Training and intervention can lead to the implementation of new policies and procedures, increased IPV screening, and increased documentation (Ambuel et al. 2013).

\section{The Current Study}

The aim of this follow-up, descriptive case study was to describe the documentation of hospitalized IPV victims and to assess whether the use of perpetrator codes improved from 2013 to 2017 compared to 2008-2012 (the baseline study). In addition, the characteristics of IPV and given care were assessed. IPV-related visits were defined from the hospital database and electronical medical records using ICD-10 coding.

\section{Methods}

This follow-up descriptive study was carried out using a Finnish central hospital's database and electronical medical records. The study was conducted to describe the documentation of IPV patients during the five-year period from January 1, 2013, to December 31, 2017. The baseline data were collected from the same hospital from 2008 to 2012 (Blinded et al. 2016). Research permit standards were carefully followed to conduct this research. The study was approved by the medical director of the hospital district ( $\mathrm{n} \S 175)$. Permissions from the hospital's ethical committee and the National Institute for Health and Welfare were not necessary because the data consisted only of one health care district's hospital database and because the patients were not contacted (Ministry of Social Affairs and Health 2012; Tays 2017). All the data were handled confidentially, and the participants' anonymity was ensured. 
First, the perpetrator codes for assaults (X85-Y09) were obtained from the hospital database, which uses the Finnish clinical modification of the ICD-10 (ICD-10-CM). Perpetrator codes are part of the secondary codes and can be used in interpersonal violence cases. In the U.S. version, code Y07 designates the perpetrator's relationship in an assault, whereas Y07.0 designates "spouse or partner, perpetrator of assault" (WHO 2016). The Finnish version differs, and Y07 does not designate the perpetrator, but the additional fourth and fifth character of the three-character assault codes (X85-Y09) does (National Institute for Health and Welfare 2011). After tracking the perpetrator codes, the three-character assault codes (X85-Y09) and the physical abuse code (T74.1) were added because the perpetrator codes might represent only the most obvious and most serious cases of IPV. The selection criteria was being 18 or older. This study excluded the code for "other forms of maltreatment" (Y07).

The sample $(N=798)$ consisted of hospital visits marked with the selected ICD-10 codes found from total visits of the hospital database for all causes $(n=2,309,538)$. To assess the characteristics of the victims, violence, and given care, the patients' electronical medical records for IPV visits were reviewed. Based on the content and information in the medical records, the violence was classified as related to or not related to a partner/ex-partner or spouse/ex-spouse $(n=110)$.

Data analysis was performed with qualitative methods using deductive content analysis. This method allows for versatile phenomena to be described in a conceptual form. In addition, it is possible to simultaneously analyze data qualitatively and quantify the data using this method. Deductive content analysis was used to systematically search for the characteristics of the victims (age, sex, relation, length of hospital visit), the perpetrators, the acts of violence, the injuries, and the given care. Contents of the medical records were analyzed by breaking the text up into conceptual parts. These parts were then classified, coded, counted, and finally categorized to describe the data (Wilson 2011). Content analysis was selected for this study because it can handle large volumes of textual data from different sources and provide evidence, particularly for sensitive topics such as IPV. Moreover, the method is commonly used in different fields such as nursing studies and social sciences (Elo and Kyngäs 2008; Wilson 2011).

\section{Results}

\section{Documentation of Violence}

The sample consisted of 798 visits from 2012 to 2017, as presented in Table 1. Of these, 423 visits $(53 \%)$ included a code for external cause of injury (X85-Y09), and 375 visits (47\%) included the physical abuse code (T74.1). The number of IPV visits increased each year. The most common code for external cause of injury was "assault by bodily force" (Y04; $21 \%)$. Overall, the number of hospital visits increased from the baseline study.

\section{The Prevalence of IPV among Hospital Patients}

Of the 798 IPV visits, 12 patients (1.5\%) had the spouse or partner perpetrator code. The number of perpetrator codes had decreased from the baseline study, presented in Table 2. The most reported type of spouse/partner-related violence was "assault by bodily force" (Y04.0) during both study periods. The least reported types were "assault by rifle, shotgun and larger firearm discharge" and "assault by blunt object."

As presented in Table 3, analysis of the essential physical abuse code T74.1 revealed various perpetrators of violence and that the overall number of these visits increased during the ten-year period (2008-2017). Over half of all visits (59\%) had a person unknown to the victim as the perpetrator or no information concerning the perpetrator. However, a fifth of patients $(21 \%)$ experienced violence caused by an ex-partner or spouse, and a fourth of visits (24\%) with the code T74.1 were partner- or spouse-related.

In total, 110 visits (13\%) were caused by IPV. These visits involved 92 victims, but only 12 of their medical records $(13 \%)$ included a perpetrator code. Hence, 80 of the patients' medical records were missing a perpetrator code. Of these missing codes, 10 patients had only a three-character external cause of injury code (X85-Y09), and 70 patients had only the essential T74.1 physical violence code. Originally, the T74.1 code consisted of 88 visits, but six were repeat patients who had both the T74.1 code and a perpetrator code from the complimentary codes X85-Y09. In addition, 12 visits were follow-up visits after the first hospital visits. On the whole, 92 patients experienced spouse- or partner-related injury.

\section{Characteristics of the Victims and Circumstances of the Violence}

In total, 92 patients experienced IPV. Most patients were identified from emergency department visits. The characteristics of the patients are presented in Table 4. The majority of the patients $(93 \%)$ were women, and of all of the patients, more than half (52\%) were 30 to 59 years old. The ages ranged from 18 to 70 years old.

Most of the perpetrators were husbands or boyfriends $(78 \%)$. One out of ten $(10 \%)$ were an ex-partner or spouse. Both men and women patients required hospital care, and $90 \%$ of the visits were during the evening or nighttime. A large proportion of patients (57\%) had missing location information. Every third (33\%) patient experienced violence at home, and the other locations included apartments, bars or restaurants, public places, and a car. Five patients were pregnant during the acts of violence. More than half (58\%) had used alcohol 
Table 1 Diagnostic codes X85-Y09 and T74.1, 2013-2017

\begin{tabular}{|c|c|c|c|c|c|c|c|}
\hline $\mathrm{X} 85-\mathrm{Y} 09$ and T74.1 $(n=798)$ & 2013 & 2014 & 2015 & 2016 & 2017 & $\mathrm{n}$ & $\%$ \\
\hline X85 Assault by drugs, medicaments, and biological substances & & & 7 & 15 & 11 & 33 & 4 \\
\hline X91 Assault by hanging, strangulation, and suffocation & 2 & 1 & & 4 & & 7 & 1 \\
\hline X94 Assault by rifle, shotgun, and larger firearm discharge & & & & & 1 & 1 & \\
\hline X95 Assault by other and unspecified firearm discharge & 3 & 3 & & 11 & 6 & 23 & 3 \\
\hline X99 Assault by sharp object & 10 & 10 & 8 & 20 & 15 & 63 & 8 \\
\hline Y00 Assault by blunt object & 2 & 11 & 1 & 2 & 7 & 23 & 3 \\
\hline Y04 Assault by bodily force & 28 & 28 & 51 & 30 & 35 & 172 & 22 \\
\hline Y05 Sexual assault by bodily force & 4 & 3 & 3 & & 2 & 12 & 1 \\
\hline Y08 Assault by other specified means & 3 & 6 & 4 & 5 & 10 & 28 & 3 \\
\hline Y09 Assault by unspecified means & 8 & 2 & 7 & 21 & 23 & 61 & 8 \\
\hline T74.1 Physical abuse & 38 & 51 & 86 & 78 & 122 & 375 & 47 \\
\hline Total & 98 & 115 & 167 & 186 & 232 & 798 & 100 \\
\hline
\end{tabular}

before the violence. The perpetrator was said to have used alcohol in $17 \%$ of the medical records. One-fourth $(24 \%)$ of the patients mentioned previous violence in their relationships. Of all the patients, more than half $(66 \%)$ had two or more diagnostic codes during the hospital visit. The number of diagnostic codes per patient varied from one to seven.

\section{Characteristics of the Violence and Given Care}

Various acts of violence were used, and more than half (59\%) of the perpetrators had used more than one act, causing several injuries $(82 \%)$. The characteristics of violence and given care are presented in Table 5.

The most common acts were hitting the head or face (36\%), throwing or flinging (30\%), strangulation $(29 \%)$, hitting an object to head (15\%), and whacking a head against something (13\%). Most of the wounds and injuries were contusions in the body $(38 \%)$ and in the head or face $(37 \%)$. Almost a third of the patients $(30 \%)$ had bodily pain. Ten fractures were reported and occurred in the eye socket, clavicle, hand, finger, tibia, and ankle.
More than half of the patients $(70 \%)$ had their vitals measured, and almost half (46\%) had some radiological examinations done during the visit. Pain medication was given to $41 \%$ of patients. Pictures were taken of the wounds and injuries in $41 \%$ of patients. In addition, police had taken pictures from five patients, and two patients had refused to be photographed. Overall, 45 patients' injuries (49\%) were photographed or offered the possibility. Child welfare reports were completed for six patients.

Of the 92 patients, $12(13 \%)$ stayed in the hospital more than one day, and one was transferred to safe house. Lengths of stay were calculated from the number of full and partial days a patient was in the hospital. Cases in which patients were admitted and discharged from the hospital on the same day were counted as one day. Of the hospitalized patients, one victim was referred to a university hospital, and two underwent operations, which were for the ankle and tibia fractures. After their first hospital visits, 15 patients were involved in 30 additional visits. Of those 30 visits, 28 were polyclinic control visits, which varied from one to seven visits per patient. Two patients had new emergency visits due to the

Table 2 Perpetrator codes, 2008-2012 and 2013-2017

\begin{tabular}{|c|c|c|c|c|}
\hline Perpetrator code & $\begin{array}{l}2008- \\
2012\end{array}$ & $\begin{array}{l}2013- \\
2018\end{array}$ & $\mathrm{n}$ & $\%$ \\
\hline X91.0 Assault by hanging, strangulation, and suffocation caused by spouse or partner & 1 & 4 & 5 & 15 \\
\hline X93.0 Assault by rifle, shotgun and larger firearm discharge caused by spouse or partner & 1 & & 1 & 3 \\
\hline X99.0 Assault by sharp object caused by spouse or partner & 3 & 2 & 5 & 15 \\
\hline Y00.0 Assault by blunt object caused by spouse or partner & 1 & 1 & 2 & 6 \\
\hline Y04.0. Assault by bodily force caused by spouse or partner & 14 & 5 & 19 & 55 \\
\hline Y05.0 Sexual assault by bodily force by spouse or partner & 1 & & 1 & 3 \\
\hline Y08.0 Assault by other specified means by spouse or partner & 1 & & 1 & 3 \\
\hline Total & 22 & 12 & 34 & 100 \\
\hline
\end{tabular}


Table 3 Relationship of the perpetrator to the victim by T74.1 code, 2008-2012 and 2013-2017

\begin{tabular}{lllll}
\hline Perpetrator & $2008-$ & $2013-$ & $\mathrm{n}$ & $\%$ \\
& 2012 & 2017 & & \\
\hline Spouse or partner & 46 & 82 & 128 & 19 \\
Ex-spouse or -partner & 10 & 6 & 16 & 2 \\
Acquaintance or friend & 45 & 84 & 129 & 20 \\
Person unknown to the victim & 123 & 91 & 214 & 33 \\
Unspecified person & 60 & 112 & 172 & 26 \\
Total & 284 & 375 & 659 & 100 \\
\hline
\end{tabular}

previous wounds or injuries. The prescribed sick-leave time for all IPV patients combined was 10 months and 3 weeks.

\section{Discussion}

Overall, 110 visits were partner- or spouse-related violence. However, the coding was insufficient, as only 12 visits

Table 4 Characteristics of patients $(n=92)$

\begin{tabular}{|c|c|c|c|}
\hline \multicolumn{2}{|l|}{ Patient (T74.1 + X85-Y09) } & \multirow{2}{*}{$\frac{\mathrm{n}}{6}$} & \multirow{2}{*}{$\frac{\%}{7}$} \\
\hline Gender & Men & & \\
\hline \multirow[t]{4}{*}{ Age } & Women & 86 & 93 \\
\hline & Under 30 & 38 & 41 \\
\hline & 30 to 59 & 52 & 57 \\
\hline & 60 or more & 2 & 2 \\
\hline \multirow[t]{5}{*}{ Perpetrator } & Husband/partner & 38 & 41 \\
\hline & Wife/partner & 4 & 4 \\
\hline & Boyfriend & 40 & 44 \\
\hline & Girlfriend & 1 & 1 \\
\hline & Ex-partner & 9 & 10 \\
\hline \multirow[t]{3}{*}{ Location } & Home & 30 & 33 \\
\hline & Other place & 9 & 10 \\
\hline & Unspecified place & 53 & 57 \\
\hline \multirow[t]{2}{*}{ Time of the hospital visit } & Daytime (06-18) & 9 & 10 \\
\hline & Evening/night (18-06) & 83 & 90 \\
\hline \multirow[t]{2}{*}{ Alcohol, patient } & Yes & 58 & 63 \\
\hline & No (or not known) & 34 & 37 \\
\hline \multirow[t]{2}{*}{ Alcohol, perpetrator } & Yes & 16 & 17 \\
\hline & No (or not known) & 76 & 83 \\
\hline \multirow[t]{3}{*}{ Length of hospital visit } & One day & 80 & 87 \\
\hline & Two days & 7 & 8 \\
\hline & Three days or more & 5 & 5 \\
\hline \multirow[t]{3}{*}{ Number of diagnostic codes } & One & 31 & 34 \\
\hline & Two & 26 & 28 \\
\hline & Three or more & 35 & 38 \\
\hline \multirow[t]{2}{*}{ Perpetrator code added } & Yes & 13 & 14 \\
\hline & No & 79 & 86 \\
\hline
\end{tabular}

(11\%) were coded with a perpetrator code. The number of perpetrator codes decreased from the baseline study even though the general number of visits with assault and physical violence codes increased. The perpetrator codes underestimate the incidences of IPV because a significant number of visits were coded only with the essential codes of the injuries. Previous studies have proven that documentation and coding are insufficient in IPV cases (Btoush et al. 2009; Schafer et al. 2008). To improve the standard of assessment and documentation, health services should train staff and use a purpose-designed IPV intervention form containing risk assessment questions and a body map (Ritchie et al. 2013).

Both men and women experienced violence, and violence was experienced in every age group. In the baseline study, most of the violence happened to those under 40 years old (57\%). However, in this follow-up study, most of the violence happened to people 30 to 59 years old (57\%). Female gender, young age, use of alcohol, and nighttime increased the risk of IPV, which is consisted with previous research (Schafer et al. 2008; Bonomi et al. 2009; Btoush et al. 2008). In comparison to other age groups, the proportion of victims above 60 or more requiring hospitalization was very small (two patients).

The rates of hospitalization were much higher in women than in men. Only six men reported IPV, and they were all over 30 years old. A previous study showed that men victims have lower rates of seeking help and that the age of these victims is usually 40 or older (Choi et al. 2015). Furthermore, although men are more likely to initiate physical contact and use physical force, women have higher levels of physical and psychological aggression. Couples with IPV arrests have elevated levels of physical and psychological aggression in both partners compared to couples not involved in an arrest incident. (Capaldi et al. 2009.) The number of men victims may be lower because men tend to underreport and hide this kind of victimization, and also because their injuries are usually mild (Carmo et al. 2011; de Macedo Bernardino et al. 2016). Men victims may be reluctant to report violence for fear of being rejected, humiliated, and ridiculed by healthcare professionals (Barber 2008; Kumar 2012).

Of cases with specific information on the location of the assault, the victim's home was most common. In line with previous literature that has shown IPV victims are more likely to be assaulted at home (Yau et al. 2013), we found for both women and men, victims assaulted at home had an elevated risk of IPV. Violence was also experienced during pregnancy. According to Almeida et al. (2017), violence during pregnancy is associated with greater odds of child physical maltreatment, which underscores the importance of screening pregnant women to prevent violence to young children at an early stage (Chan et al. 2012).

Consistent with other studies, the findings suggest that victims experience multiple superficial injuries and contusions, particularly located on the head and trunk, and present with 
Table 5 Characteristics of violence, given care, and different examinations

\begin{tabular}{|c|c|c|c|c|c|}
\hline Act of violence & $\mathrm{n}$ & Wound/injury & $\mathrm{n}$ & Given care and examinations & $\mathrm{n}$ \\
\hline Hit the head or face & 33 & Contusions in the body & 35 & Vitals & 64 \\
\hline Threw or flinged & 28 & Contusions in the head or face & & Radiologic testing & 42 \\
\hline Strangled & 27 & Bodily pain & 34 & Pain medication & 38 \\
\hline Hit head with an object & 14 & Headache & 28 & Photographing injuries & 38 \\
\hline \multirow[t]{2}{*}{ Whacked head against something } & & Headache & 26 & Mental aid/crisis intervention & 15 \\
\hline & 12 & Bruises in the body & 23 & Wound suturing & 15 \\
\hline Tore hair & 9 & Swelling in the head or face & 21 & Laboratory tests & 14 \\
\hline Twisted or pressed a limb & 9 & Bruises in the head or face & 17 & Wound care & 12 \\
\hline Kicked the body & 8 & Bump in the head & 14 & Splinting/plaster/binding & 10 \\
\hline Hit the body & 8 & Fracture & \multirow[t]{2}{*}{10} & \multirow[t]{2}{*}{ Commotion tracking instructions } & \multirow[t]{2}{*}{8} \\
\hline Kicked the head & 6 & Momentary & & & \\
\hline Threatened verbally & 6 & unconsciousness & 9 & Cold bag & 8 \\
\hline Hit body with an object & 5 & Swelling in the body & 8 & Child welfare report & 6 \\
\hline Stabbed & 5 & Visual symptoms & 8 & Wound care instructions & 5 \\
\hline Sat on & 4 & Nausea & 7 & Antibiotic & 5 \\
\hline Bit & 3 & Bit & 7 & Operation & 2 \\
\hline Pressed/Tore face & 3 & Stabbing wound & 6 & Tetanus-vaccine & 2 \\
\hline Insulted & 2 & Vomiting & 5 & Gynecological examination & 2 \\
\hline Held onto & 2 & Dizziness & 4 & Eyes flushing & 1 \\
\hline Hit body with an object & 1 & Nosebleed & 3 & \multirow[t]{2}{*}{ Patient guidelines for violence } & \multirow[t]{2}{*}{1} \\
\hline Sexual violence & 1 & Bite wound & 2 & & \\
\hline Threatened with a knife & 1 & Bleeding from the ear & 2 & Plaster therapy patient instructions & 1 \\
\hline & & Broken or swinging tooth & 2 & & \\
\hline \multirow[t]{2}{*}{ Pressed hand to mouth and nose } & 1 & Molten eye or eyes & 2 & & \\
\hline & 1 & Loss of hearing & 1 & & \\
\hline \multirow[t]{9}{*}{ Pepper sprayed face } & & Limping & 1 & & \\
\hline & & Nail traces in the body & 1 & & \\
\hline & & Broken hair & 1 & & \\
\hline & & Brain injury & 1 & & \\
\hline & & Hematoma in the eye & 1 & & \\
\hline & & Gynecological bleeding & 1 & & \\
\hline & & Bleeding from the mouth & 1 & & \\
\hline & & Hard to open mouth & 1 & & \\
\hline & & Humming in ears & 1 & & \\
\hline Total & 189 & & 283 & & 289 \\
\hline
\end{tabular}

bodily pain (Danielle et al. 2015; Perciaccante et al. 2010; Yau et al. 2013). Both physical and psychological violence can be lethal. Most of the IPV victims subjected to any kind of physical violence feel that their lives are in danger during the abuse. Moreover, during psychological violence, victims that feel their lives are in danger are threatened verbally to be killed. (Vatnar and Bjørkl 2013.)

The majority of patients received radiologic testing, wound care, and pain medications, as in a previous study (Btoush et al. 2009). Most of the injury photographs were taken by nurses, but some were taken by police. However, photographs were not always taken, and the patient guidelines for violence were distributed to only one patient. According to Deutsch et al. (2017), victims are rarely asked about injuries unless they are immediately visible. Photographs are important for all victims seeking legal remedy. The hospitalization of IPV victims hospital was costly to society because of the several diagnoses, hospital admissions, follow-ups, and sick-leave involved. Most of the patients stayed in the hospital for one to three days and were then discharged with follow-ups, like in a previous study (Chan et al. 2013).

\section{Methodological Considerations}

This study has several limitations. First, the participants represented patients only from a single-district, central 
hospital in Finland, which is a relatively small study sample $(N=798)$. Second, the lack of IPV identification, documentation, and proper coding were the major limitations of this study. Third, violence is still a very sensitive issue, and the results can be affected by denial. Some patients may state a false reason for their injuries (such as an accident instead of violence).

\section{Conclusion}

This results of this study suggest a great need for health services to improve documentation and coding of IPV. The poor use of perpetrator codes underestimates the incidences of violence and minimizes their usefulness for surveillance. Various patients in different healthcare settings can have an IPV background. A lack of general preparedness to identify and care for victims can lead to many patients not receiving appropriate care and treatment. Multidisciplinary collaboration between health, legal, and social service professionals is needed to provide comprehensive care.

The perpetrator codes are not used enough even though they strengthen the completeness of perpetrator documentation. Health professionals' knowledge and awareness are crucial in the identification and documentation of IPV. There is a need to implement guidelines and screening tools to enhance identification, documentation, and victim care. More research is needed to determine effective methods to improve identification, documentation, and proper coding of victims.

The following recommendations for supporting providers in improving documentation can be drawn from the results of this study:

1. Careful documentation of IPV and especially the use of proper perpetrator codes improves the visibility of the problem and its impact on the victims, families and health services.

2. The identification of IPV requires careful negotiation of the prerequisites and courage to ask and suspect the possibility of violence.

3. With the identified IPV and close multidisciplinary collaboration, violence reduction and injury prevention can be significantly improved.

Acknowledgements The authors are grateful for the hospital district's cooperation.

Author Contributions All authors contributed to the study concept and design. SK and JR contributed in the data collection, and SK in the analysis and the drafting of the manuscript. EP, TL, JR, and HP provided critical revision of the manuscript. All authors read and approved the final manuscript.
Open Access This article is distributed under the terms of the Creative Commons Attribution 4.0 International License (http:// creativecommons.org/licenses/by/4.0/), which permits unrestricted use, distribution, and reproduction in any medium, provided you give appropriate credit to the original author(s) and the source, provide a link to the Creative Commons license, and indicate if changes were made.

\section{References}

Almeida, F., Coutinho, E., Duarte, J., Chaves, C., Nelas, P., Amaral, O., \& Parreira, V. (2017). Domestic violence in pregnancy: Prevalence and characteristics of the pregnant woman. Journal of Clinical Nursing, 26, 2417-2425. https://doi.org/10.1111/jocn.13756.

Ambuel, B., Hamberger, K., Guse, C., Melzer-lange, M., Phelan, M., \& Kistner, A. (2013). Healthcare can change from within: Sustained improvement in the healthcare response to intimate partner violence. Journal of Family Violence, 28(8), 833-847. https://doi.org/10. 1007/s10896-013-9550-9.

Barber, C. F. (2008). Domestic violence against men. Nursing Standard, 22(51), 3-39.

Ben Natan, M., Ben Ari, G., Bader, T., \& Hallak, M. (2012). Universal screening for domestic violence in a department of obstetrics and gynecology: A patient and carer perspective. International Nursing Review, 59(1), 108-114.

Bonomi, A., Anderson, M., Reid, R., Rivara, F., Carrel, D., \& Thompson, R. (2009). Medical and psychosocial diagnoses in women with a history of intimate partner violence. Archives of Internal Medicine, 169, 1692-1697. https://doi.org/10.1001/archinternmed.2009.292.

Bradbury-Jones, C., Taylor, J., Kroll, T., \& Duncan, F. (2014). Domestic abuse awareness and recognition among primary healthcare professionals and abused women: A qualitative investigation. Journal of Clinical Nursing, 23(21-22), 3057-3068. https://doi.org/10.1111/ jocn.12534.

Breiding, M. J., Basile, K. C., Smith, S. G., Black, M. C., \& Mahendra, R. R. (2015). Intimate partner violence surveillance: Uniform definitions and recommended data [PDF]. Retrieved from https://www. cdc.gov/violenceprevention/pdf/ipv/intimatepartnerviolence.pdf. Accessed 17 Feb 2018.

Btoush, R., Campbell, J., \& Gebbie, K. (2008). Visits coded as intimate partner violence in emergency departments: Characteristics of the individuals and the system as reported in a national survey of emergency departments. Journal of Emergency Nursing, 34, 419-427. https://doi.org/10.1016/j.jen.2007.10.015.

Btoush, R., Campbell, J., \& Gebbie, K. (2009). Care provided in visits coded for intimate partner violence in a national survey of emergency departments. Women's Health Issues, 19, 253-262. https://doi. org/10.1016/j.whi.2009.03.004.

Capaldi, D. M., Shortt, J. W., Kim, H. K., Wilson, J., Crosby, L., \& Tucci, S. (2009). Official incidents of domestic violence: Types, injury, and associations with nonofficial couple aggression. Violence and Victims, 24(4), 502-519. https://doi.org/10.1891/0886-6708.24.4.502.

Carmo, R., Grams, A., \& Magalhães, T. (2011). Men as victims of intimate partner violence. Journal of Forensic and Legal Medicine, 18, 355-359. https://doi.org/10.1016/j.jflm.2011.07.006.

Chan, K., Brownridge, D., Fong, D., Tiwari, A., Leung, W., \& Ho, P. (2012). Violence against pregnant women can increase the risk of child abuse: A longitudinal study. Child Abuse \& Neglect, 36, 275284. https://doi.org/10.1016/j.chiabu.2011.12.003.

Chan, K., Choi, W., Fong, D., Chow, C., Leung, M., \& Ip, P. (2013). Characteristics of family violence victims presenting to emergency departments in Hong Kong. The Journal of Emergency Medicine, 44(1), 249-258. https://doi.org/10.1016/j.jemermed.2012.01.061.

Choi, A., Wong, J., Kam, C.-W., Lau, C.-L., Wong, J., \& Lo, R. (2015). Injury patterns and help-seeking behavior in Hong Kong male 
intimate partner violence victims. The Journal of Emergency Medicine, 49(2), 217-226. https://doi.org/10.1016/j.jemermed. 2015.03.007.

Costa, B., Kaestle, C., Walker, A., Curtis, A., Day, A., Toumbourou, J., \& Miller, P. (2015). Longitudinal predictors of domestic violence perpetration and victimization: A systematic review. Aggression and Violent Behavior, 24, 261-272. https://doi.org/ 10.1016/j.avb.2015.06.001.

Curca, G. C., Dermengiu, D., \& Hostiuc, S. (2012). Patterns of injuries in domestic violence in a Romanian population. Journal of Interpersonal Violence, 27(14), 2889-2902. https://doi.org/10. $1177 / 0886260512438278$.

Danielle, M., Larrabee, H., \& Davis, S. (2015). United States emergency department visits coded for intimate partner violence. The Journal of Emergency Medicine, 48(1), 94-100. https://doi.org/10.1016/j. jemermed.2014.07.053.

de Macedo Bernardino, Í., Barbosa, K. G. N., da Nóbrega, L. M., Cavalcante, G. M. S., de Castro Martins, R., \& d'Avila, S. (2016). Profile of men who are victims of physical violence by an intimate partner. Journal of Family Violence, 31, 617-624. https://doi.org/10. 1007/s10896-016-9815-1.

de Macedo Bernardino, Í., Santos, L. M., Ferreira, A. V. P., de Almeida Lima, T. L. M., da Nóbrega, L. M., \& d'Avila, S. (2018). Intimate partner violence against women, circumstances of aggressions and oral-maxillofacial traumas: A medical-legal and forensic approach. Legal Medicine, 31, 1-6. https://doi.org/ 10.1016/j.legalmed.2017.12.001.

Deutsch, L., Resch, K., Barber, T., Zuckerman, Y., Thompson, J., \& Cerulli, C. (2017). Bruise documentation, race and barriers to seeking legal relief for intimate partner violence survivors: A retrospective qualitative study. Journal of Family Violence, 32, 767-773. https://doi.org/10.1007/s10896-017-9917-4.

Ellonen, N., Piispa, M., Peltonen, K., \& Oranen, M. (2013). Exposure to parental violence and outcomes of child psychosocial adjustment. Violence and Victims, 28(1), 3-15. https://doi.org/10.1891/08866708.28.1.3.

Elo, S., \& Kyngäs, H. (2008). The qualitative content analysis process. Journal of Advanced Nursing, 62(1), 107-115. https://doi.org/10. 1111/j.1365-2648.2007.04569.x.

García-Moreno, C., Jansen, H.A., Ellsberg, M., Heise, L., \& Watts, C. (2005) WHO multi-country study on women's health and domestic violence against women. Initial results on prevalence, health outcomes and women's responses. World Health Organization. Retrieved February 10, 2018, from http://www.who.int/ reproductivehealth/publications/violence/24159358X/en/. Accessed 10 Feb 2018.

Kivelä, S., Leppäkoski, T., Kälvinmäki, J., Ruohoniemi, J., Puolijoki, H., \& Paavilainen, E. (2016). How intimate partner violence appears in healthcare. Journal of Social Medicine, 53, 98-107.

Kivelä, S., Leppäkoski, T., Helminen, M., \& Paavilainen, E. (2018). A cross-sectional descriptive study of the family functioning, health and social support of hospital patients with family violence backgrounds. Scandinavian Journal of Caring Sciences, 32(3), 10831092. https://doi.org/10.1111/scs.12554.

Koistinen, I., \& Holma, J. (2015). Finnish health care professionals' views of patients who experience family violence. SAGE Open, 5(1), 215824401557039. https://doi.org/10.1177/2158244015570392.

Krug, E. G., Dahlberg, L. L., Mercy, J. A., Zwi, A. B., \& Lozano, R. (2002). World report on violence and health [PDF]. Retrieved from http://apps.who.int/iris/bitstream/10665/42495/ 1/9241545615_eng.pdf.

Kumar, A. (2012). Domestic violence against men in India: A perspective. Journal of Human Behavior in the Social Environment, 22(3), 290-296. https://doi.org/10.1080/10911359.2012.655988.

Leppäkoski, T., Åstedt-Kurki, P., \& Paavilainen, E. (2010). Identification of women exposed to acute physical intimate partner violence in an emergency department setting in Finland. Scandinavian Journal of Caring Sciences, 24(4), 638-647. https://doi.org/10.1111/j.14716712.2009.00754.x.

Leppäkoski, T., Flinck, A., \& Paavilainen, E. (2014). Assessing and enhancing health care providers' response to domestic violence. Nursing Research and Practice., 2014, 1-8. https://doi.org/10. 1155/2014/759682.

Leppäkoski, T., Flinck, A., \& Paavilainen, E. (2015). Greater commitment to the domestic violence training is required. Journal of Interprofessional Care, 29(3), 281-283. https://doi.org/10.3109/ 13561820.2014.955913.

Linnarsson, J. R., Benzein, E., Årestedt, K., \& Erlingsson, C. (2013). Preparedness to care for victims of violence and their families in emergency departments. Emergency Medicine Journal, 30, 198201. https://doi.org/10.1136/emermed-2012-201127.

Matteoli, M., Piacentino, D., Kotzalidis, G. D., Serata, D., Rapinesi, C., Angeletti, G., Rossi, M., David, V., \& De Dominicis, C. (2016). The clinical and radiological examination of acute intimate partner violence injuries: A retrospective analysis of an Italian cohort of women. Violence and Victims, (1), 31, 85-102. https://doi.org/10.1891/ 0886-6708.VV-D-14-00107.

McCauley, M., Head, J., Lambert, J., Zafar, S., \& van den Broek, N. (2017). Keeping family matters behind closed doors: Healthcare providers' perceptions and experiences of identifying and managing domestic violence during and after pregnancy. BMC Pregnancy and Childbirth, 17, 318. https://doi.org/10.1186/s12884-017-1520-4.

National Institute for Health and Welfare. (2011). Tautiluokitus ICD-10: Klassifikation av sjukdomar [Third edition of the Finnish version of the International Statistical Classification of Diseases and Related Health Problems] [PDF]. Retrieved from https://thl.fi/documents/ 10531/1449887/ICD-10.pdf/8091c7cc-fda6-4e86-8ef97790d8d6a1a2. Accessed 16 Oct 2018.

Nittis, M., Hughes, R., Gray, C., \& Ashton, M. (2013). Domestic violence documentation project 2012. Journal of Forensic and Legal Medicine, 20(6), 683-689. https://doi.org/10.1016/j.jflm. 2013.04.002.

Perciaccante, V., Carey, J., Susarla, S., \& Dodson, T. (2010). Markers for intimate partner violence in the emergency department setting. Journal of Oral and Maxillofacial Surgery, 68, 1219-1224. https:// doi.org/10.1016/j.joms.2010.02.010.

Reid, R., Bonomi, A., Rivara, F., Anderson, M., Fishman, P., Carrell, D., \& Thompson, R. (2008). Intimate partner violence among men: Prevalence, chronicity, and health effects. The American Journal of Preventive Medicine, 34(6), 478-485. https://doi.org/10.1016/j. amepre.2008.01.029.

Ritchie, M., Nelson, K., Wills, R., \& Jones, L. (2013). Does training and documentation improve emergency department assessments of domestic violence victims? Journal of Family Violence, 28, 471-477. https://doi.org/10.1007/s10896-013-9514-0.

Ruddle, A., Pina, A., \& Vasquez, E. (2017). Domestic violence offending behaviors: A review of the literature examining childhood exposure, implicit theories, trait aggression and anger rumination as predictive factors. Aggression and Violent Behavior, 34, 154-165. https://doi. org/10.1016/j.avb.2017.01.016.

Schafer, S., Drach, L., Hedberg, K., \& Kohn, M. (2008). Using diagnostic codes to screen for intimate partner violence in Oregon emergency departments and hospitals. Public Health Reports, 123(5), 628-635. https://doi.org/10.1177/003335490812300513.

Tays. (2017). Ethical guidelines of the ethics Committee of the Tampere region. Retrieved November 30, 2017, from https://www.tays.fi/fiFI/Tutkimus_ja_opetus/Tutkimus/Eettinen_toimikunta/ Toimintaohje/Eettisen_toimikunnan_toimintaohje(50365). Accessed 30 Nov 2017.

The Ministry of Social Affairs and Health. (2012). Potilasasiakirjojen laatiminen ja käsittely. Opas terveydenhuollolle [drawing up and handling of patient documents: Guide for health care professionals] 
[PDF]. Retrieved from http://julkaisut.valtioneuvosto.fi/bitstream/ handle/10024/72897/URN\%3aNBN\%3afi-fe201504225719.pdf? sequence=1\&isAllowed=y. Accessed 20 Feb 2019.

Trojan, C., \& Krull, A. (2012). Variations in wounding by relationship intimacy in homicide cases. Journal of Interpersonal Violence, 27(14), 2869-2888. https://doi.org/10.1177/0886260512438285.

Vatnar, S. K., \& Bjørkl, S. (2013). Lethal intimate partner violence: An interactional perspective on women's perceptions of lethal incidents. Violence and Victims, 28, 772-789.

Widom, C. S., Czaja, S., \& Dutton, M. A. (2014). Child abuse and neglect and intimate partner violence victimization and perpetration: A prospective investigation. Child Abuse \& Neglect, 38, 650-663. https:// doi.org/10.1016/j.chiabu.2013.11.004.

Wilson, V. (2011). Research methods: Content analysis. Evidence Based Library and Information Practice, 11(1(S), 41-43. https://doi.org/ 10.18438/B8CG9D.

World Health Organization (2010). Preventing intimate partner and sexual violence against women: Taking action and generating evidence [PDF]. Retrieved from http://www.who.int/violence_injury prevention/publications/violence/9789241564007 eng.pdf. Accessed 2 Feb 2017.

World Health Organization (2013). Global and regional estimates of violence against women: Prevalence and health effects of intimate partner violence and nonpartner sexual violence [PDF]. Retrieved from http:// apps.who.int/iris/bitstream/10665/85239/1/9789241564625_eng.pdf. Accessed 20 Feb 2017.

World Health Organization. (2016). ICD-10: International statistical classification of diseases and related health problems (5th ed.) Malta: WHO library cataloguing-in-publication data.

World Health Organization. (2018). ICD-11: Classifying disease to map the way we live and die. Retrieved June 29, 2018, from http://www. who.int/health-topics/international-classification-of-diseases. Accessed 29 June 2018

Yau, R., Stayton, C., \& Davidson, L. (2013). Indicators of intimate partner violence: Identification in emergency departments. The Journal of Emergency Medicine, 45(3), 441-449. https://doi.org/10.1016/j. jemermed.2013.05.005.

Zilkens, R. R., Smith, D. A., Kelly, M. C., Mukhtar, S. A., Semmens, J. B., \& Phillips, M. A. (2017). Sexual assault and general body injuries: A detailed cross-sectional Australian study of 1163 women. Forensic Science International, 279, 112-120. https://doi.org/10. 1016/j.forsciint.2017.08.001.

Publisher's Note Springer Nature remains neutral with regard to jurisdictional claims in published maps and institutional affiliations. 